\title{
The influence of virtual reality on design process creativity in basic design studios
}

\author{
Samah Obeid (1) and Halime Demirkan \\ Department of Interior Architecture and Environmental Design, I. D. Bilkent University, Ankara, Turkey
}

\begin{abstract}
With the recent advancements in digital technologies, the design studios are transformed to virtual environments that offer both to design students and instructors a broader perspective in understanding the design process. As an integral part of design process, the supporting virtual tools enhance creativity in basic design studios. This study examines the influence of immersive and non-immersive virtual design environments on design process creativity in the first year basic design studio, through observing the factors related to creativity as the flow state and motivation. Consequently, an experiment is conducted to investigate the relationships between spatial ability, flow state and motivation in immersive and non-immersive virtual design environments. Forty-two first-year undergraduate basic design students participated in the experiment. The data analysis demonstrated that the immersive virtual design environment facilitates participants' design process creativity more than the non-immersive one. Also, the findings indicated a positive strong correlation between motivations and flow state and a positive weak correlation between spatial ability and flow state. Study results contributed to a greater understanding of implementing immersive virtual reality as a creativity supporting tool.
\end{abstract}

\section{ARTICLE HISTORY}

Received 18 May 2020

Accepted 27 November 2020

\section{KEYWORDS}

Creativity; digital educational technologies; flow state; motivation; spatial ability; virtual reality

\section{Introduction}

Recent developments in technology have impacted almost every aspect of life such as the way people live, work, communicate and teach (Yang et al., 2019). Consequently, much research is carried out to understand how and to what extent these developments in technology affect people's lives. Inevitably, technology has a major impact on the learning environments that results in much research mostly focusing on learning and teaching processes. Since these developments in technology shape, the way students learn and educators deliver material, design instructors should keep up with the newest and recent teaching methods and digital technologies that improve the learning and teaching processes (Yalcinalp \& Avci, 2019). For the efficient implementation of these technologies, more research is needed on their possible applications and for the future learning opportunities.

In design process, one should have certain skills in problem-solving process as well as in accumulating the design knowledge (Demirkan \& Hasirci, 2009). A great number of students experience difficulties in external representation of their ideas in 2D drawings or 3D models, even when they have adequate design knowledge (Kaur et al., 2019). Mostly, this is explained by the difficulty in understanding the design problem using the traditional instructional materials or in external representation of design ideas using the traditional tools (Kaur et al., 2019). Since mental imagery 
and external representation are the two essential components of creativity (Hasirci \& Demirkan, 2007), it is necessary to develop and implement both methods and materials that enable students in forming the mental imagery of something that does not exist and external representation of it. Thus, the digital technologies have the potential as the supporting tools to facilitate the design process and improve the design solutions.

Virtual reality (VR) technologies are applied in various design fields such as architecture, computer graphics, engineering design and others (Sun et al., 2019). They enable designers and design students to discover and communicate their ideas with greater ease (Pausch et al., 1993; Schnabel et al., 2008; Sopher et al., 2019). VR technology, as an essential and interactive tool, provides a medium to express ideas and overcome the technical gap between mental imagery and external representation in design process (Ran \& Zhenbiao, 2011).

VR could be classified into immersive and non-immersive technologies (Liu et al., 2011) and in education; virtual design environments (VDEs) could be classified into two categories as being, immersive and non-immersive (Vergara et al., 2015). Immersive VDE is a simulated environment that enables the users to interact with the virtual space, in a somewhat real way, with the aid of devices such as a headset and controllers (Riva, 2006), whereas, a non-immersive VDE is referred to as a computer-generated environment that enables the users to interact with the virtual space through a display screen (Vergara et al., 2015). Thus, immersive VDEs allow the users to experience 3D environments in a higher sense (Pausch et al., 1993).

\section{Creativity}

Recently, the amount of studies on digital technologies supporting creativity is expanding (Mishra \& The Deep-Play Research Group, 2012). One of the most recently studied topics in the twenty-first century is the influence of digital technologies on students' creativity in design education (Yalcinalp \& Avci, 2019). Understanding the interaction between creativity and technology is crucial for design instructors, since both concepts are complex and essential to design education (Mishra \& Henriksen, 2018a, 2018b).

Digital tools support people in generating and communicating knowledge in the development of creative ideas (Greene, 2002; Harley et al., 2016). Moreover, many individuals require the assistance of tools that facilitate creativity in order to develop creative designs and products (Gabriel et al., 2016). Additionally, environments that support creativity facilitate the generation of creative designs in the early stage of design with an influence on design outcomes (Karakaya \& Demirkan, 2015).

Due to the complex nature of creativity, there is no concise definition that comprises all the characteristics of creativity (Demirkan \& Afacan, 2012; Horn \& Salvendy, 2006). Lately, a large amount of research has focused on investigating the creativity factors in various fields, such as in neurology, cognitive science, personality traits, social environments and cultural systems (Hennessey \& Amabile, 2010). In design, a creative process is described mostly as an internal process consisting of an exploration of a mental imagery occurring in designer's mind and transforming it to an external representation (Demirkan, 2010). In this research, creativity is defined as the creative transition that arises between the problem and solution phases of a design, and is investigated by the assessment of three main components of creativity in design process, namely as spatial ability, flow state and motivation.

\section{Factors influencing creativity in design process}

\section{Spatial ability}

Spatial ability is the capacity to represent, transform, induce and generate physical and abstract information (Linn \& Petersen, 1985). The term spatial ability covers a range of abilities mainly related to $2 \mathrm{D}$ and $3 \mathrm{D}$ mental representations. Design students and designers should have high spatial ability, so they can easily understand and translate 2D and 3D spatial relations (Ho, 2006; McKim, 1972; Oxman, 2002). According to Pandey et al. (2015), a student with a higher spatial ability is able to provide more creative solutions. A designer's ability to imagine 3D spaces highly 
affects the design outcome and the reflected design quality (Cho, 2017). Although creativity and spatial ability were found as significant factors in design process, limited research exists on their relationship and role in design process (Cho, 2017).

\section{Flow state}

Jackson and Marsh (1996) define the flow state as a positive observational state that occurs when the performer is completely linked to the performance, with the condition that the skills of the performer match with the challenges of the task. Moreover, Bhatt (2004) showed that immersion is significantly correlated with the state of flow. Immersion is described as a mental state of a user in the VR tool experience when they feel totally separated from the real world (Yang et al., 2018). Being highly immersed in a situation facilitates the generation of creative ideas (Csikszentmihalyi, 1996; Witmer \& Singer, 1998). Moreover, Veale et al. (2013) found that the flow state is a crucial factor in creative design process that influences the designer's creative performance. The flow state scale (FSS) developed by Jackson and Marsh (1996) covers the nine dimensions defined by Csikszentmihalyi (1996), namely as, challenge-skill balance, action-awareness merging, clear goals, unambiguous feedback, concentration on task at hand, sense of control, loss of self-consciousness, transformation of time and autotelic experience.

\section{Motivation}

Keller and Litchfield (2002) define motivation as the students' desire to participate in a learning environment. Motivation is a major component that stimulates and improves learning performance (Gagné, 1985; Keller, 1987). Moreover, Sha et al. (2012) stated that motivation has an impact on the learning process and performance and as a consequence, motivation at low level prevents learner's success (Jeamu et al., 2008). Keller and Suzuki (2004) identified four components of learning process that affect motivation as attention, relevance, confidence and satisfaction (ARCS). They explained them as a variety of strategies that are integrated to gain learners' attention (Attention), clear goals that are defined and the instructions that are relevant to the learners past experience (Relevance), a learning environment that helps learners to develop a feeling of success (Confidence), and attaining a satisfactory feeling from the activity (Satisfaction) (Keller \& Suzuki, 2004).

In interior architecture education, design studios are the learning environments where students learn the basic principles of design (Sopher et al., 2019). In design studios, students develop their design knowledge while generating solutions for design problems under the supervision of an expert design instructor in the sessions called as critiques (Schön, 1987). Design studio environment influences students' understanding of basic design thinking, action and theory (Schön, 1985). According to Denel (1998), among design courses, basic design is considered as a foundation course, since it introduces the fundamental design principles initially in design education. In basic design studios, students are exposed both to theory and practice that help them in developing the required skills for the later stages of design education.

Varinlioglu et al. (2015) demonstrated that the implementation of digital tools in early design process significantly influences the design outcomes of students. Varinlioglu et al. (2015) claimed that when digital environments are experienced in early design stages, students tend to participate more enthusiastically in the process and are more motivated to solve the advanced design problems. Furthermore, in defining the relationship between the digital environment and the problem-solving process, Vandeleur et al. (2001) stated that creativity relevant processes are explicit indicators of creativity and are essential for creativity to occur.

\section{Literature review}

Previous studies showed that creativity support tools are crucial to the development of new ideas and creative designs (Gabriel et al., 2016; Klein \& Dologite, 2000; Shneiderman, 2007; Wang \& Nickerson, 2017). Also, Forgionne and Newman (2007) stated that creativity support tools assist designers 
in solving complex problems. Moreover, Shneiderman (2002) claimed that creativity support tools eliminate the expertise barriers and cost limitations in developing different design solutions in real environments, thus, making designers more motivated towards accomplishing tasks in a creativity supporting environment. Also, design researchers investigated several methods that stimulate and support creativity, especially in education (Shneiderman et al., 2006), by developing a set of design principles with the aim to facilitate the development of creativity support tools. Their main focus was on software and environments where individuals would be able to generate, modify, interact and share artifacts.

Several studies demonstrated the positive effects of VR applications in education and training of students, as they received the significant and interactive feedbacks in virtual environments (Atilola et al., 2016; Carrozzino \& Bergamasco, 2010; Hussein \& Nätterdal, 2015; Jou \& Wang, 2013; Kilmon et al., 2010; Merchant et al., 2014; Thorsteinsson, 2013). A previous study conducted by Yang et al. (2018) compared the effects of two interactive environments, as the paper-andpencil and immersive VR environments, on individual creativity. The findings of the study showed that the immersive VR environment's participants had higher quality creative products compared to the paper and pencil environment's ones. Besides previous studies demonstrated that VR tools, such as games, simulations and environments, could improve learning and education (Lau \& Lee, 2015; Merchant et al., 2014). VDEs were found to be appropriate for design process, as they reduce the creation time and costs, and improve the quality and usability of new designs (Teklemariam et al., 2014). Thus, Teklemariam et al. (2014) claimed that it is necessary to integrate VR in design education that requires research on design applications in this domain. VR was found by Teklemariam et al. (2014) as the appropriate tool for speeding up the decision making process in early design stages. However, uses of immersive VDEs were rarely observed in design process both in professional and design education environments (Antonieta, 2015).

In this respect, this study aims to investigate the VDEs for design instructors that facilitate students' design creativity. This study explores the influence of immersive and non-immersive VDEs on design process through observing the factors of creativity as spatial ability, flow state and motivation. Previous studies examined the relationships between creativity and spatial ability, flow or motivation separately, but did not examine them all together (Pandey et al., 2015; Wei et al., 2015; Yang et al., 2018). Furthermore, these studies generally observed the creativity factors either in traditional or VDEs. By examining these factors together in two VDEs, immersive and non-immersive, this study aims to offer different perspectives on the understanding of creativity in design process and the ways to facilitate it. As a result, the research questions of the present study are proposed as follows:

(1) Is there a difference in design process creativity between immersive and non-immersive VDEs?

(2) As creativity factors, how spatial ability, flow state and motivation influence the design process in immersive and non-immersive VDEs?

(3) Are the creativity factors (spatial ability, flow state and motivation) independent of each other?

\section{Method}

\section{Research design and framework}

The objective of this study is to explore the influence of immersive and non-immersive VDEs on individual's creativity and provide design instructors the means to facilitate and support creativity in design process. This paper proposes a framework for observing the factors of creativity in design process that are based on the previous literature. These factors that support creativity are spatial ability, flow state and motivation in VDEs (Figure 1). 


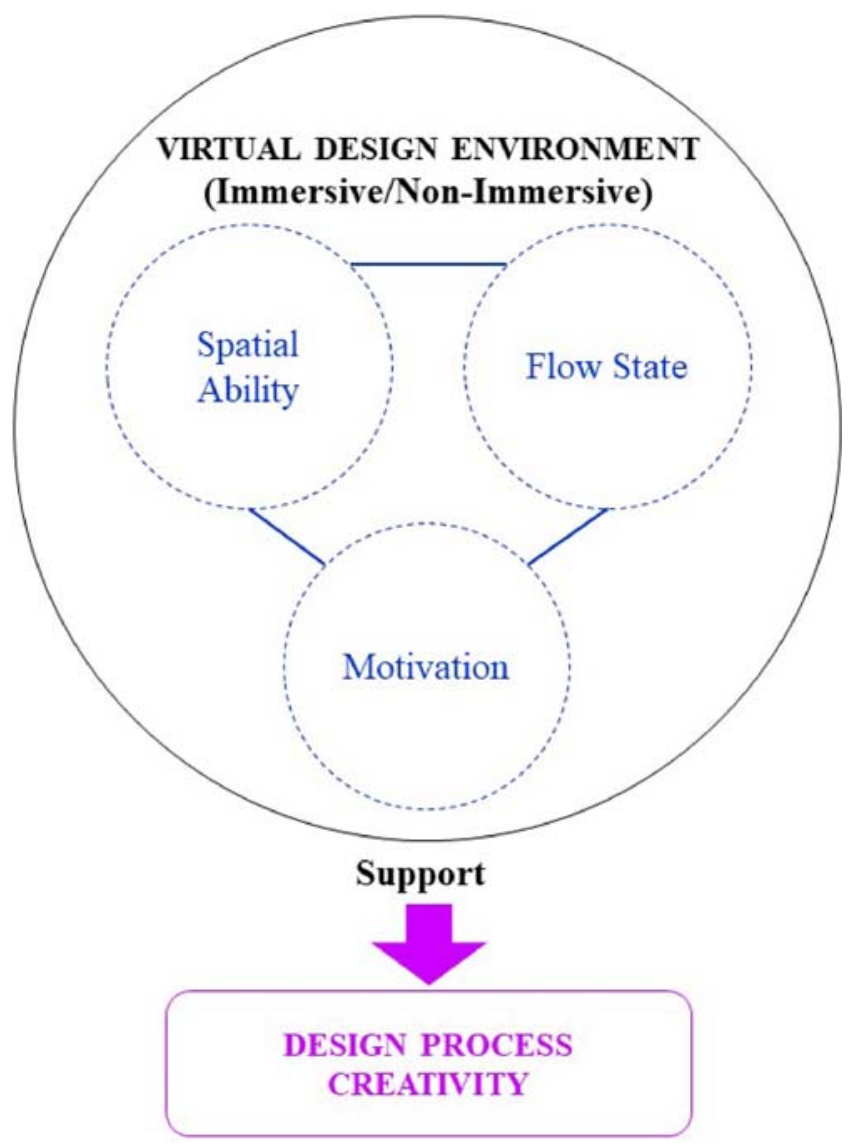

Figure 1. Conceptual framework of the study.

\section{Participants}

Before starting the experiment, the approval of the ethics committee at I.D. Bilkent University was obtained (No: 2019_03_27_02). A total of 42 first-year Basic Design course students of the Department of Interior Architecture and Environmental Design at I.D. Bilkent University were recruited for the study. Twenty-one participants ( 12 female and 9 male) solved the design task in an immersive VDE using Oculus Rift DK2, while the other 21 participants (17 female and 4 male) solved the design task in a non-immersive VDE using iPad mini A1432. I.D. The selection of the participants was based on the simple random sampling method materialized by defining the population of the study as firstyear Basic Design course students enrolled in the 2018-2019 spring semester. Participants were informed about the experiment by the researcher and they voluntarily signed up for participation. Participants were randomly assigned to the immersive and the non-immersive VDE groups, where if the first participant joined the immersive group the second person joined the nonimmersive group, thus, each student had an equal chance of being selected into both groups (Figures 2 and 3).

\section{Design tools}

In each VDE, one design tool was used to complete the design task; Oculus Rift with Touch controllers or iPad mini A1432. The Oculus Rift DK2 is a high tech VR tool consisting of a headset, two wireless controllers and two sensors (Figure 4). The Oculus Rift displays a resolution of $1080 \times 1200$ pixels 


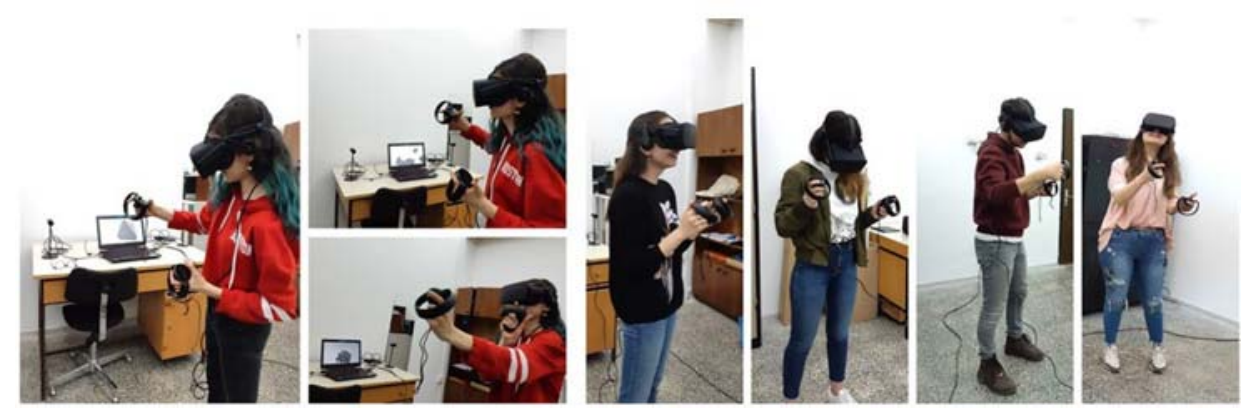

Figure 2. Participants in the immersive VDE.
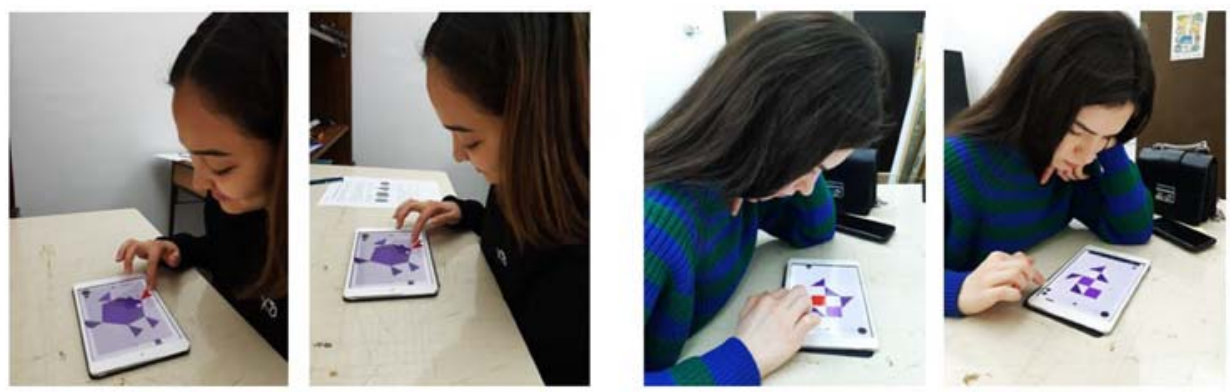

Figure 3. Participants in the non-immersive VDE.
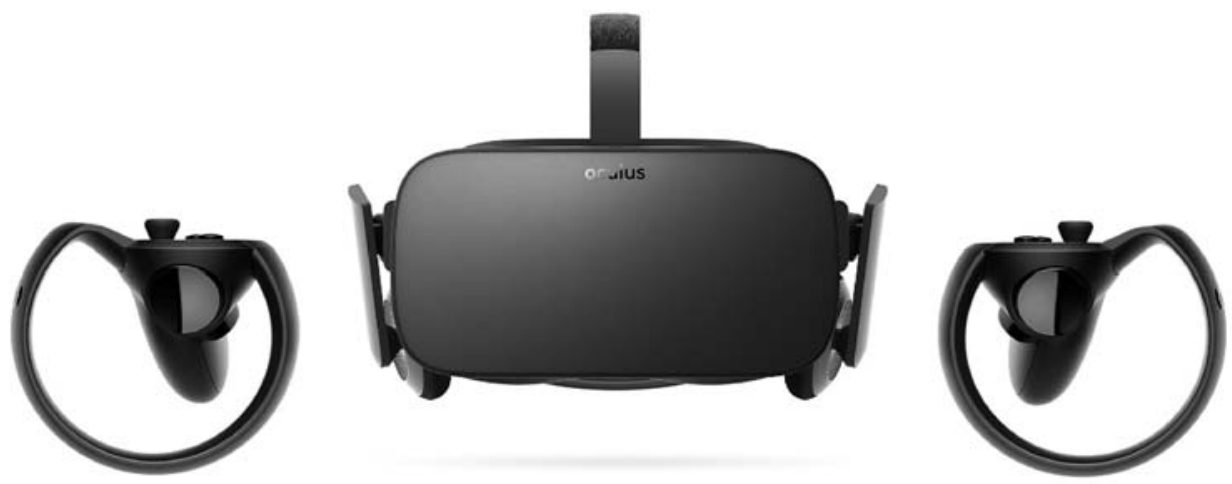

Figure 4. Oculus Rift + Touch tool, retrieved from https://www.oculus.com

per eye with a frame rate of $90 \mathrm{~Hz}$. The Oculus Rift enabled the participants to feel present in the virtual design space, where they could create virtual objects and move them freely around.

The iPad displays a resolution of $1024 \times 768$ pixels at 163 ppi. The iPad allowed the user's to perceive the VDE through its flat screen. Thus, the iPad is defined as a non-immersive virtual environment tool (Vergara et al., 2017). In contrast with the immersive VDE, the participants in the nonimmersive VDE were not able to interact with the virtual environment, nor were they able to walk around their design.

For the design task, Gravity Sketch Software is used in both immersive and non-immersive VDEs. Gravity Sketch is an intuitive and 3D modeling design software that offers a variety of options and 

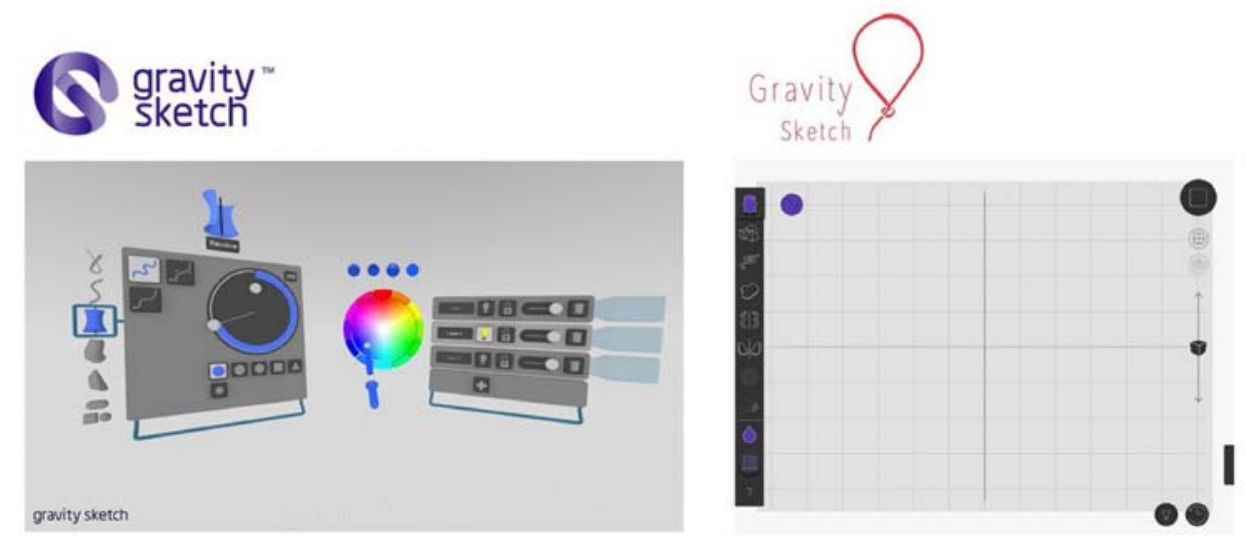

Figure 5. To the left, Gravity Sketch software in Immersive VDE, to the right Gravity Sketch software in Non-immersive VDE (screen shots taken by author).

tools allowing participants to create regular geometric shapes that could be moved, rotated, scaled, copied and combined in all directions. Thus, the immersive VDE consisted of the Oculus Rift headset associated with the gravity sketch software, whereas the non-immersive VDE consisted of the iPad associated with the gravity sketch software (Figure 5).

\section{Design task}

In the design task, the participants had to develop a creative 3D composition that considers meaningful combinations, either following a certain sequence, pattern or order of the geometric forms using the fundamental basic design principles. The participants used the regular geometric forms offered by the Gravity Sketch Software as comprised of cylinder, prism, pyramid and sphere. As a task requirement, the $3 \mathrm{D}$ composition was only limited in the total number of forms, with a minimum of 8 and a maximum of 16 geometric forms, and there was no limitation in the number of each geometric form.

\section{Instruments}

Five instruments were used to assess the participants' performance during the experiment. Table 1 lists the measured variables in each instrument and their developers.

\section{The students' questionnaire}

The students' questionnaire included information about the participants' demographic variables, such as gender and age. Also, it measured the participants' familiarity with VR tools by involving questions on previous experience with VR, type of used VR tool, purpose and frequency of use.

\section{The mental rotation test (MRT)}

The mental rotation test (MRT) was used to assess the participants' spatial ability. Previous studies demonstrated the reliability of MRTs in many design research areas (Caissie et al., 2009; Gorska \& Sorby, 2008; Sorby, 2007). The MRT test used in the current study was a redrawn figures version of the original Shepard and Metzler's (1971) test and was used with the permission of Dr. Michael Peters (Peters et al., 1995). Reliability of the original instrument was found satisfactory where retest correlation was reported as 0.83 (Vandenberg \& Kuse, 1978). In the later study by Peters et al. (1995), the researchers compared the reliability of the two tests and stated, "there were no significant differences in performance on the two test forms" (p.48). 
Table 1. Measured variables and used instruments used to assess participants' responses.

\begin{tabular}{lllc}
\hline Order & \multicolumn{1}{c}{ Measured variables } & \multicolumn{1}{c}{ Instruments } & Developed by \\
\hline 1 & $\begin{array}{l}\text { Demographic variables and VR } \\
\text { familiarity }\end{array}$ & The Students' Questionnaire & The researcher \\
2 & $\begin{array}{l}\text { Spatial ability } \\
\text { Degree of presence }\end{array}$ & $\begin{array}{c}\text { The Mental Rotation Test (MRT) } \\
\text { The Presence Questionnaire }\end{array}$ & $\begin{array}{c}\text { Peters et al. (1995) } \\
\text { Witmer and Singer } \\
(2005)\end{array}$ \\
4 & Flow state of mind & The Flow State Scale (FSS) & Jackson and Marsh \\
& Design motivation & (1996) & Keller (2010) \\
\hline
\end{tabular}

\section{The presence questionnaire}

In virtual environments, Witmer and Singer (1998) define presence as the intuitive experience of feeling totally present in a virtual space, while actually being physically situated in another one. Thus, the effectiveness of a VR experience was measured by the level of presence experienced by the participants in that VR space (Antonieta, 2015). The Presence Questionnaire (PQ) was used to assess the degree of presence experienced by the participants in the immersive VDE on a 7-point Likert scale. The degree of presence was usually assessed by a questionnaire given to the users after experiencing a VR scene (Schwind et al., 2019). The PQ originally included 32 items, then, in a later study by Witmer and Singer (2005) the items were reduced to 19 .

\section{The flow state scale (FSS)}

As a self-assessment survey instrument, the FSS indicates the flow state level of an individual in a certain situation that includes 36 items on a 5-point Likert scale (Jackson \& Marsh, 1996). Jackson and Marsh (1996) verified the reliability of the scale with a sample of 394 where Cronbach's alpha of FSS full items is at any rate 0.8 . The FSS was used to assess the flow state of participants, both in the immersive and non-immersive VDEs.

\section{The instructional materials motivation survey (IMMS)}

The IMMS as a self-assessment instrument of perception of motivation was used to measure participants' motivation levels towards design process. As applied by Wei et al. (2015), the questionnaire includes 19 items on a 5-point Likert scale.

\section{Procedure}

The first phase of the experiment consists of a short training period that provides an equal proficiency to all participants in using the 3D design software, Gravity Sketch; and the two instruments, the Oculus Rift and iPad. Prior to the experiment, all participants completed the demographic questionnaire involving information about their demographic characteristics as age and gender, and amount of experience with VR. In order to identify the level of participants' spatial ability, participants were then asked to complete the MRT that consists of 24 items. Each item consists of a depiction of 3D target figure and four test figures consisting of two identical to the target but rotated from the original position by a certain amount, or else showed two figures that were not only rotated but also the mirror image of the target. The participants were required to indicate the two correctly rotated test figures. As mentioned in the instruction section of the redrawn MRT, participants were restricted in time in $3 \mathrm{~min}$ for the first 12 items then, after a short break, 3 more minutes were given to solve the remaining 12 items. The experiment procedure is shown in Figure 6.

Later, both groups were presented with the identical design task. Participants in the immersive VDE were asked to use the Oculus Rift DK2 for the design task (Figure 7), while the participants in 


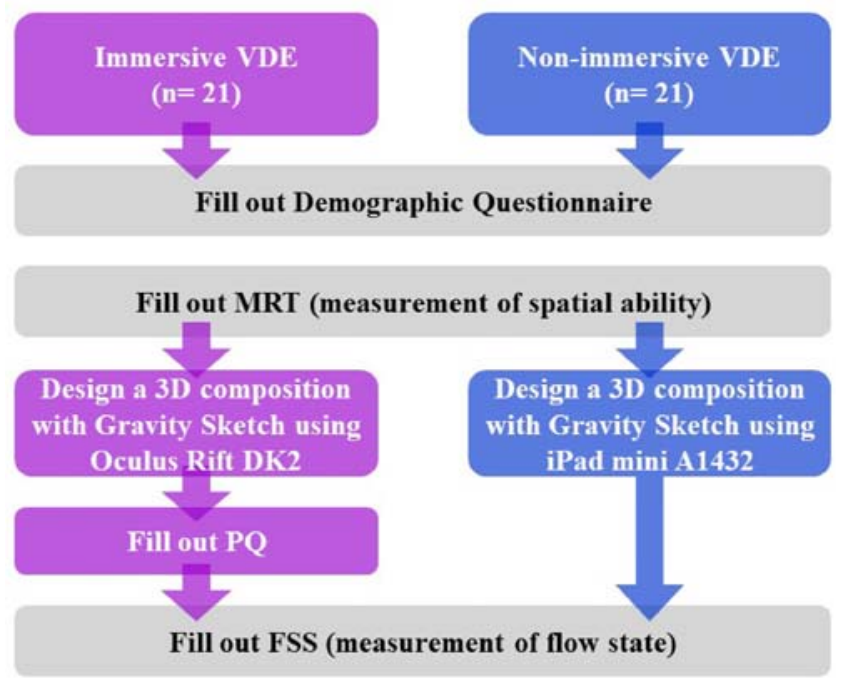

\section{Fill out IMMS (measurement of motivation)}

Figure 6. Procedure of the study.

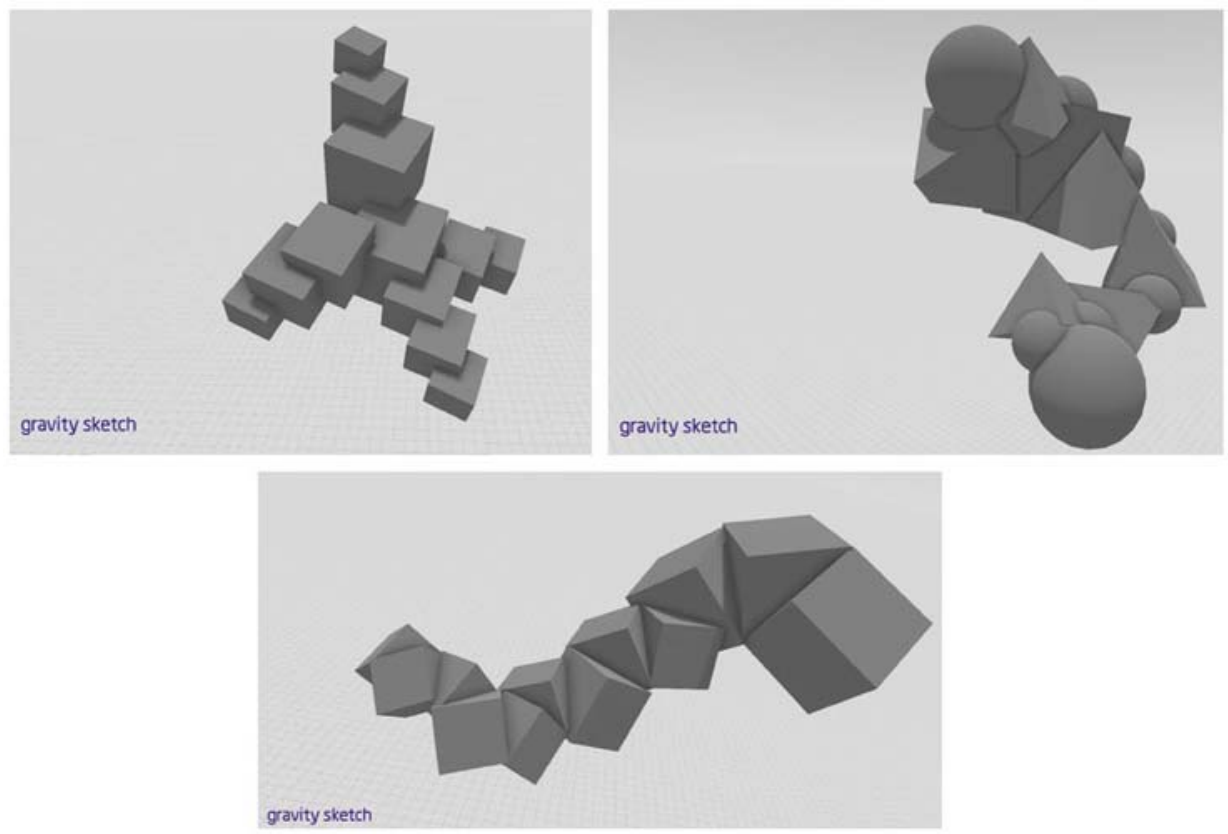

Figure 7. Sample of the participants' designs in the immersive VDE.

the non-immersive VDE were asked to create their designs using iPad mini A1432 (Figure 8). Upon the completion of the design task, the participants of the immersive VDE completed the PQ in order to evaluate their experience with the immersive environment. Later, to assess the experienced flow state and motivation levels, all participants completed the FSS and IMMS that were distributed at the end of the design task. 


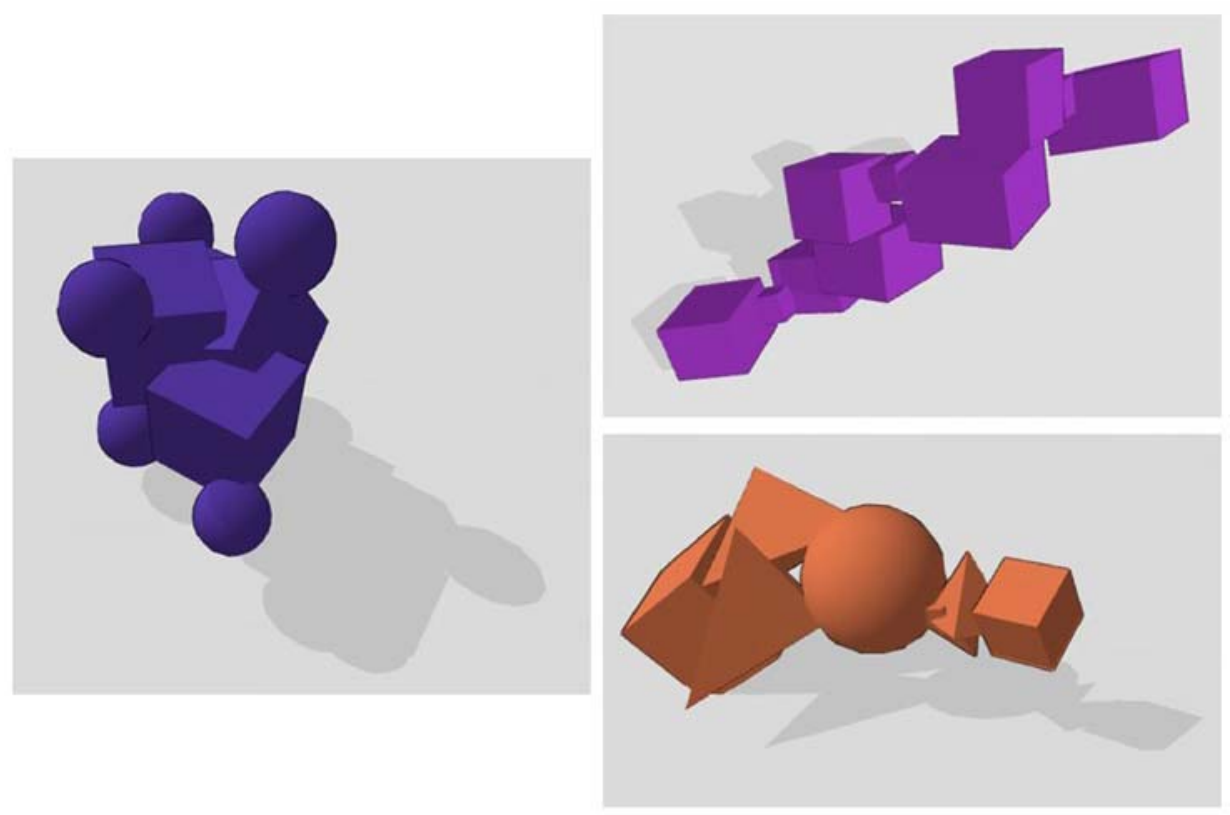

Figure 8. Sample of the participants' designs in the non-immersive VDE.

\section{Data analysis}

All quantitative data were analyzed by using the Statistical Package for Social Sciences (SPSS, version 21) software. Descriptive statistics, including means and standard deviations, were used to calculate participants' responses to the Students' Questionnaire about the demographic characteristics. This study adopted Cronbach's a coefficient in order to evaluate the internal consistency reliability of the Flow State, Motivation and Spatial Ability tests. Then, mean scores were calculated and Independent samples t-tests were conducted in order to examine the influence of immersive and non-immersive VDEs on design process creativity. Lastly, correlation and independence analyses tests were done in order to investigate the relationship between spatial ability, flow state and motivation.

\section{Results}

The experiment was conducted with 42 participants who were first-year basic design students in 2018-2019 spring semester. Twenty-one participants designed the product in an immersive VDE where 12 of them were females and 9 of them were males with a mean age of 20.24 (SD $=1.136$ ). While the other half of the sample designed the product in a non-immersive VDE where 17 of them were females and 4 were males with a mean age of 20.14 (SD =1.062). Overall, among the participants 29 were females and 13 were males. The age range of the participants was between 19 and 23 years. The average age of the participants was 20.19 years $(S D=1.087)$.

The results of the Students' Questionnaire showed that among 42 participants, only 14 (33.3\%) of the participants were familiar, while 28 (66.7\%) of them were unfamiliar with VR tools (Table 2). Thus, the majority of participants were unfamiliar with VR tools.

Among 21 immersive VDE's participants, only 10 were familiar with the VR tools and the familiar ones mostly (six) have used VR tools for game purposes. Among 21 non-immersive VDE's participants, only four used VR tools and they have used similarly either for game playing or other purposes as visiting online museums. None of the participants have used VR tools for design purposes in both VDEs. VR tool usage frequency was similar in the two VDEs and was stated as 1-2 times previously 
Table 2. Demographic characteristics of the participants in the two VDEs.

\begin{tabular}{lcc}
\hline Characteristics & Immersive VDE & Non-immersive VDE \\
\hline Number & 21 & 21 \\
Participant age (years) & 20.24 & 20.14 \\
Mean & $18-23$ & $18-23$ \\
Range & 12 & 17 \\
Participant gender & 9 & 4 \\
Female & & 4 \\
Male & 10 & 2 \\
Participant history & & - \\
Previously used VR & 6 & 2 \\
Previously used VR in & 2 & 4 \\
Games & 2 & - \\
Research & 7 & 4 \\
Other & 3 & \\
No. of times VR usage & & \\
1-2 times & 10 & \\
3-5 times & & \\
Last time VR usage & & \\
More than 2 months ago & & \\
\hline
\end{tabular}

used. Also, the participants of both VDEs that were familiar with VR tools have used these tools more than 2 months ago.

\section{Presence questionnaire analysis}

The mean score range for each participant was from 3.79 to 7 where score 1 indicated a low sense of presence, 4 a medium sense of presence and 7 a high sense of presence. The results of the PQ demonstrated that the participants of the immersive VDE experienced a positive high sense of presence with a mean score of 5.35 (SD $=0.667$ ), indicating that the virtual environment provided a sufficient sense of presence.

\section{Mental rotation test analysis}

The maximum score that could be received on the MRT was 24 . The results of the MRT showed that the participants of the immersive VDE had a mean score of 10.48 (SD =5.93), while the participants of the non-immersive VDE had a mean score of $9.00(S D=4.57)$.

\section{Reliability analysis}

Reliability analyses for the FSS and IMMS instruments were explored in terms of Cronbach's alpha coefficients, in order to determine the internal consistency of the total items and their subscales. According to Bowling (2014), an alpha value of 0.5 and above indicated a good internal consistency. Cronbach's alpha scores for the FSS and IMMS scales were 0.957 and 0.933 , respectively, which each indicated a very strong reliability of the scale. Cronbach's alpha scores for the FSS nine subscales were $0.913,0.772,0.882,0.861,0.864,0.906,0.877,0.668$ and 0.867 , respectively, and for the IMMS four subscales were $0.74,0.85,0.657$ and 0.875 , respectively, which demonstrated that all subscales had a high reliability and internal consistency.

\section{Flow experience analysis}

The flow state experience was measured by using the FSS survey on a 5-point Likert scale. The calculated mode $\left(M_{0}\right)$ values indicated that the majority of the participants in the immersive VDE experienced a high state of flow $\left(M_{\mathrm{o}}=4\right.$ agree) and in the non-immersive VDE as a neutral state of flow $\left(M_{\circ}\right.$ 
$=3$ nor disagree or agree). The median $\left(M_{\mathrm{d}}\right)$ values were calculated as 3 (nor disagree or agree) both for immersive and non-immersive VDEs at a scale of 5 . The difference in the $M_{0}$ values between groups indicated that the majority of the participants in the immersive environment experienced a higher state of flow compared to those in the non-immersive environment.

Independent samples t-tests were conducted to compare the flow experiences of the participants in the immersive and non-immersive VDEs. The results showed no significant difference in the flow experience ratings of participants between the two VDEs $(t=1.609 ; \mathrm{df}=40 ; p=.115)$. The immersive VDE group gave a total mean score of $3.78(S D=0.712)$, whereas the non-immersive VDE group gave a total mean score of 3.45 ( $S D=0.634$ ) for all questions indicating a small mean difference between two groups. The mean scores for the FSS subscales demonstrated a slight difference between the immersive and non-immersive environments throughout all subscales (Table 3). Furthermore, the independent samples t-test analysis showed that there were no significant differences between the two VDEs in terms of the subscales Challenge-Skill Balance, Action-Awareness Merging, ClearGoals, Unambiguous Feedback, Concentration on Task at Hand, Paradox of Control, Loss of Self-Consciousness and Transformation of Time (Table 3). However, in terms of Autotelic Experience, the $t$ test results indicated a significant difference between the immersive and the non-immersive VDEs $(t=4.14 ; \mathrm{df}=40 ; p=.0001)$.

\section{Instructional materials motivation survey analysis}

In order to compare the motivation level that the participants' experienced in both environments, the $M_{o}$ and $M_{d}$ values of the IMMS were calculated. The calculated $M_{0}$ and $M_{d}$ values indicated that the majority of the participants in the immersive VDE were highly motivated $\left(M_{\mathrm{o}}\right.$ and $M_{\mathrm{d}}=4$ agree), while the participants in the non-immersive VDE were moderately motivated $\left(M_{\mathrm{o}}\right.$ and $M_{\mathrm{d}}$ $=3$ nor disagree or agree).

Independent samples t-tests were conducted to compare the motivation level of the participants in the two VDEs. The results showed a significant difference in the motivation level of the participants between the immersive and the non-immersive VDEs $(t=2.971 ; \mathrm{df}=40 ; p=.005)$. The immersive VDE group has a total mean score of $4.17(S D=0.651)$, whereas the non-immersive VDE group has a total mean score of $3.55(S D=0.679)$ for all questions indicating that the immersive environment provided the participants with a higher level of motivation. According to the IMMS analysis, the immersive VDE enabled the students to feel more motivated towards the design task as it allowed them to experience the overall design process, somehow, in a real environment.

Table 3. Results of the mean scores and independent samples t-test for the FSS by subscales.

\begin{tabular}{|c|c|c|c|c|c|c|}
\hline Scales & Environment & $M$ & SD & $t$ & $\mathrm{df}$ & Sig. (2-tailed) \\
\hline \multirow[t]{2}{*}{ Challenge-Skill Balance } & Immersive & 3.74 & 0.937 & 1.093 & 40 & 0.281 \\
\hline & Non-immersive & 3.43 & 0.898 & & & \\
\hline \multirow[t]{2}{*}{ Action-Awareness Merging } & Immersive & 3.40 & 0.804 & 0.632 & 40 & 0.531 \\
\hline & Non-immersive & 3.24 & 0.903 & & & \\
\hline \multirow[t]{2}{*}{ Clear-Goals } & Immersive & 3.46 & 0.936 & 1.192 & 40 & 0.24 \\
\hline & Non-immersive & 3.12 & 0.941 & & & \\
\hline \multirow[t]{2}{*}{ Unambiguous Feedback } & Immersive & 3.37 & 0.846 & 1.421 & 40 & 0.163 \\
\hline & Non-immersive & 3.01 & 0.781 & & & \\
\hline \multirow[t]{2}{*}{ Concentration on Task at Hand } & Immersive & 3.89 & 1.045 & 0.448 & 40 & 0.657 \\
\hline & Non-immersive & 3.76 & 0.838 & & & \\
\hline \multirow[t]{2}{*}{ Paradox of Control } & Immersive & 4.00 & 1.135 & 1.576 & 40 & 0.123 \\
\hline & Non-immersive & 3.49 & 0.963 & & & \\
\hline \multirow[t]{2}{*}{ Loss of Self-Consciousness } & Immersive & 3.92 & 1.013 & 0.481 & 40 & 0.633 \\
\hline & Non-immersive & 3.76 & 1.071 & & & \\
\hline \multirow[t]{2}{*}{ Transformation of Time } & Immersive & 3.68 & 0.729 & 0.642 & 40 & 0.525 \\
\hline & Non-immersive & 3.54 & 0.713 & & & \\
\hline \multirow[t]{2}{*}{ Autotelic Experience } & Immersive & 4.57 & 0.565 & 4.14 & 40 & 0.0001 \\
\hline & Non-immersive & 3.68 & 0.811 & & & \\
\hline
\end{tabular}


Table 4. Results of the mean scores and independent samples t-test for the IMMS by subscales.

\begin{tabular}{|c|c|c|c|c|c|c|}
\hline Scales & Environment & $M$ & SD & $t$ & $\mathrm{df}$ & Sig. (2-tailed) \\
\hline \multirow[t]{2}{*}{ Attention } & Immersive & 4.19 & 0.592 & 4.229 & 40 & 0.0001 \\
\hline & Non-immersive & 3.39 & 0.635 & & & \\
\hline \multirow[t]{2}{*}{ Relevance } & Immersive & 4.10 & 0.864 & 2.312 & 40 & 0.026 \\
\hline & Non-immersive & 3.51 & 0.768 & & & \\
\hline \multirow[t]{2}{*}{ Confidence } & Immersive & 4.02 & 0.792 & 2.071 & 40 & 0.045 \\
\hline & Non-immersive & 3.46 & 0.94 & & & \\
\hline \multirow[t]{2}{*}{ Satisfaction } & Immersive & 4.39 & 0.661 & 2.479 & 40 & 0.017 \\
\hline & Non-immersive & 3.84 & 0.766 & & & \\
\hline
\end{tabular}

The mean scores for the IMMS subscales indicated a significant difference between the immersive and non-immersive environments throughout all subscales (Table 4). The results reported by the participants of the immersive VDE has a mean score of higher than 4 in each subscale, indicating that the experiment captured participants' attention, was relevant to their studies, left them confident and provided them with a satisfactory designing experience. The independent samples t-test results showed a significant difference between groups in terms of all subscales (Table 4). On the attention factor, the t-test results indicated that the immersive VDE captured the attention of the participants greater than the non-immersive VDE throughout the experiment $(t=4.229 ; \mathrm{df}=40 ; p$ $=.0001)$. On the relevance factor, the $t$-test results revealed that the content of the immersive VDE was more relevant to the participants than the content of the non-immersive VDE $(t=2.312$; $\mathrm{df}=40 ; p=.026$ ). Thus, the participants in the immersive VDE were more willing to participate in the designing process. For the impact on the confidence scale, the t-test results suggested a significant difference between the two environments $(t=2.071 ; \mathrm{df}=40 ; p=.045)$. These results indicated that the options provided by the immersive VDE helped the participants in enhancing their self-confidence in designing. Lastly, on the satisfaction factor, the $t$-test results demonstrated that the design process was more satisfying for the participants in the immersive VDE $(t=2.479$; $\mathrm{df}=40 ; p=.017)$.

\section{Correlation and independence analyses}

The relationships between spatial ability, flow experience and motivation were analyzed using bivariate correlation analysis. Furthermore, Spearman's rho correlation $\left(r_{s}\right)$ and Chi-square test for independence $\left(x^{2}\right)$ tests were conducted. As seen in Table 5, the results of the correlation tests indicated a positive strong relationship between the flow state and motivation factors $\left(r_{s}=0.71 ; p\right.$ $=.0001)$ and a positive weak relationship between the spatial ability and flow state factors $\left(r_{s}=\right.$ $0.32 ; p=.039$ ). There was no significant relationship between the spatial ability and motivation factors (Figure 9).

Furthermore, the results of the chi-square tests showed that spatial ability and flow state are not independent of each other $\left(x^{2}=9.827 ; \mathrm{df}=4 ; p=.043\right)$. Also, results indicated that motivation and flow state are not independent of each other $\left(x^{2}=16.189 ; \mathrm{df}=4 ; p=.003\right)$.

Table 5. Results of the bivariate relationships among variables.

\begin{tabular}{llcc}
\hline Factors & \multicolumn{1}{c}{ Spearman's rho } & Spatial ability & Flow state \\
\hline Spatial Ability & Correlation coefficient & 1.000 & $0.32^{\text {a }}$ \\
Flow State & Sig. (2-tailed) & $\cdot$ & 0.039 \\
& Correlation coefficient & - & 1.000 \\
Motivation & Sig. (2-tailed) & - &. \\
& Correlation coefficient & 0.189 & $0.713^{\mathrm{b}}$ \\
& Sig. (2-tailed) & 0.229 & 0.0001 \\
\hline
\end{tabular}

\footnotetext{
${ }^{\text {a } C o r r e l a t i o n ~ i s ~ s i g n i f i c a n t ~ a t ~ t h e ~} 0.05$ level (2-tailed).
}

${ }^{b}$ Correlation is significant at the 0.01 level (2-tailed). 


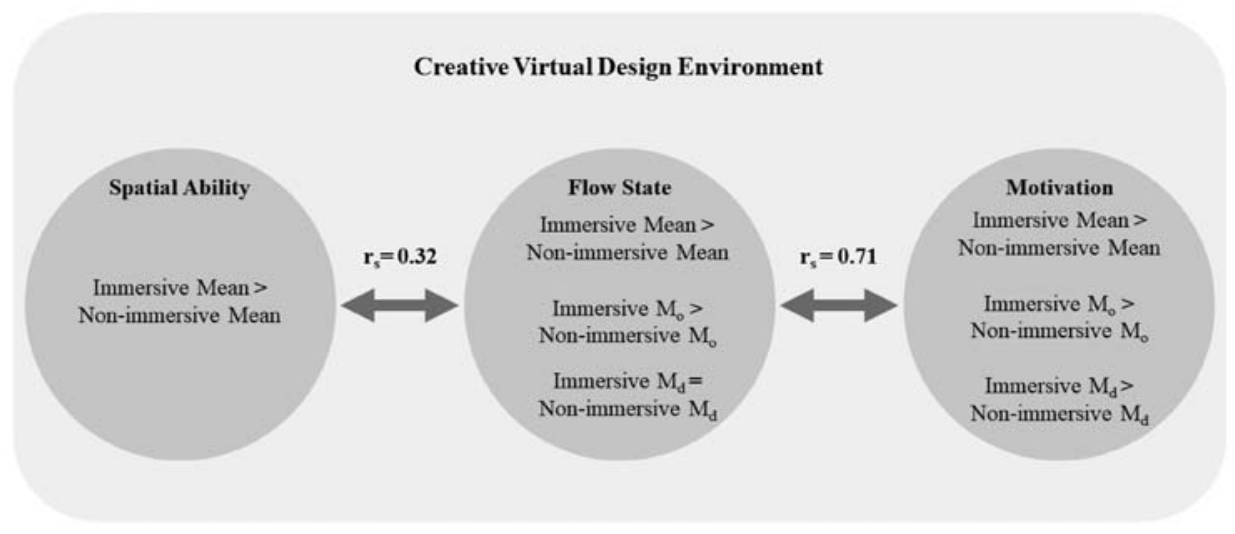

Figure 9. Summary of the findings of the study.

\section{Discussion}

This study examined the influence of immersive and non-immersive VDEs on design process creativity in basic design studios, through observing factors related to creativity as the spatial ability, flow state and motivation. The results demonstrated that all participants had a successful experience with the VDEs. However, the participants in the immersive VDE had higher spatial ability levels than those in the non-immersive VDE. Moreover, compared with the non-immersive VDE, the immersive VDE allowed the participants to feel more motivated and experienced a higher state of flow, resulting in higher design process creativity. The independent t-test results indicated that there is no significant difference in the flow state level of participants between the immersive and non-immersive VDEs. However, the findings of this study are not in line with the previous findings by Yang et al. (2018) where a significant difference was found in the flow state between the two design environments. This inconsistency with Yang et al.'s (2018) study could be a result of the nature of the compared design environments. The researchers in Yang et al.'s (2018) study compared immersive VDE with a traditional design environment (paper and pencil), while the present study compared an immersive with a non-immersive VDE. Therefore, both group of participants in the present study experienced a VDE with technological tools that allowed them to enter somehow a similar state of flow. Furthermore, in the Yang et al.'s (2018) study, the reported significant difference could be because of the great difference between the tools and options that a virtual and a real design environment offer to the users.

Compared with a non-immersive VDE, the additional features of an immersive VDE, such as 3D perspective and full-body involvement, could influence one's creative thinking and behavior (Yang et al., 2018). Many studies examined the effects of immersive VDE on design creativity through the comparison with traditional environments where a significant difference exists between the tools, options and sources provided to the participants. However, as far as one can tell from the literature, no study considered comparing immersive with non-immersive VDEs in terms of factors related to design creativity. Therefore, this study to the best knowledge of authors is a pioneer study that compares the immersive VDE with the non-immersive VDE in design process creativity. The findings demonstrated that, compared with the non-immersive VDE, the immersive VDE offered the participants with a higher sense of involvement with the design task. Furthermore, the findings indicated that the most significant difference between the immersive and non-immersive VDEs was in terms of FSS's Autotelic Experience subscale. Csikszentmihalyi (1996) claimed that an activity is autotelic when the individual experiences high senses of purpose and curiosity towards an activity, thus, the individual is more involved with the activity. Furthermore, an autotelic individual requires little tools because the activity they are doing is already 
rewarding (Csikszentmihalyi, 1996). Therefore, participants in the immersive VDE experienced a greater rewarding experience than the participants in the non-immersive VDE.

This study examined motivation based on the ARCS model composed of four components, which are attention, relevance, confidence and satisfaction. Fink and Benedek's (2014) study demonstrated a high correlation between creative ideas and attention. Another study by Nusbaum and Silvia (2011) reported that creativity depends on attention. However, in the literature, no study was found that investigates the influence of immersive VR on the motivation of students' as a factor related to design process creativity. The results showed a significant difference in motivation between both groups. The participants of the immersive VDE were more motivated in the design task than those in the non-immersive VDE. Therefore, the findings of the study demonstrated that the immersive $\mathrm{VDE}$, where participants experienced body involvement in the design process, allowed participants to experience a higher state of flow and made them feel more motivated. The findings are in line with Yang et al.'s (2018) study that demonstrated that immersive VR influenced attention.

The findings of the study demonstrated that immersive VDE had a significant influence on flow and motivation and therefore, on design process creativity. Results, also, demonstrated a significant correlation between spatial ability and flow state, and between motivation and flow state. The findings indicated that the immersive VDE influences significantly design process creativity. Also, the results showed a significant relationship between spatial ability and design process creativity. The study findings led us to a deeper understanding of the impact and relationship between immersive VR, spatial ability, motivation, flow state and design process creativity.

\section{Conclusion}

In today's design world, the implementation of immersive VR technologies is becoming very common, especially in basic design education. Studies about creativity support environments and creativity factors are also, recent topics in research on basic design education. However, educational institutions are not yet, able to adapt to this rapid development of creativity support tools. Today, design instructors aim to develop students' design skills without paying much attention to their creativity skills or even more important to the factors that affect their design creativity. The findings of this study could provide new insights to design instructors for means that facilitate and support design creativity. In fact, this study presented to design instructors the importance of creativity factors on design process. The results also emphasized the importance of a holistic understanding of design students' abilities and factors that influence design process in education.

\section{Limitations and future research}

The present study is subject to some limitations. First, only two main factors related to creativity, flow state and motivation, were considered in this study. Thus, other factors should be considered in further studies such as, the individuals' initial creativity and motivation levels for the task. Second, most of the participants were unfamiliar with the VR tool and the design software, Gravity Sketch, used in this study. Therefore, it should be noted that technologies and new tools could add tension to the user that could affect their performance in a positive or negative way. Therefore, the individuals' levels of stress and relaxation during the design task should be assessed as well. Lastly, due to the limited available tools and time restrictions, this study carried a small sample size of 42 design students with small significant differences. Thus, a study with a greater number of participants should be considered and it would be interesting to see if the same feature of immersive VDE "body involvement" would still provoke a significant difference between immersive and non-immersive VDEs. Thus, a study with a larger sample should be considered. Still, much research is needed to understand the individual and environmental factors influencing creativity. 


\section{Disclosure statement}

No potential conflict of interest was reported by the author(s).

\section{Notes on contributors}

Samah Obeid is a PhD candidate at the Department of Interior Architecture and Environmental Design, I. D. Bilkent University. Her research focuses on creativity and virtual reality applications for design.

Halime Demirkan is a Professor of Architecture at the Department of Interior Architecture and Environmental Design and the Director of the Graduate School of Economics and Social Sciences at I. D. Bilkent University. Her current research interests include creativity, design education, and human-computer interaction.

\section{ORCID}

Samah Obeid (D) http://orcid.org/0000-0001-7151-5579

Halime Demirkan (D) http://orcid.org/0000-0002-2055-3089

\section{References}

Antonieta, A. (2015). Rediscovering Virtual Reality in the Education of Architectural Design: The immersive simulation of spatial experiences. Ambiances [Online]. doi:10.4000/ambiances.594.

Atilola, O., Tomko, M., \& Linsey, J. S. (2016). The effects of representation on idea generation and design fixation: A study comparing sketches and function trees. Design Studies, 42, 110-136. https://doi.org/10.1016/j.destud.2015.10.005

Bhatt, G. (2004). Bringing virtual reality for commercial web sites. International Journal of Human-Computer Studies, 60(1), 1-15. https://doi.org/10.1016/j.ijhcs.2003.07.002

Bowling, A. (2014). Research methods in health: Investigating health and health services. McGraw-Hill Education (UK).

Caissie, A. F., Vigneua, F., \& Bors, D. A. (2009). What does the mental rotation test measure? An analysis of item difficulty and item characteristics. The Open Psychology Journal, 2(1), 94-102. https://doi.org/10.2174/1874350100902010094

Carrozzino, M., \& Bergamasco, M. (2010). Beyond virtual museums: Experiencing immersive virtual reality in real museums. Journal of Cultural Heritage, 11(4), 452-458. https://doi.org/10.1016/j.culher.2010.04.001

Cho, J. Y. (2017). An investigation of design studio performance in relation to creativity, spatial ability, and visual cognitive style. Thinking Skills and Creativity, 23, 67-78. https://doi.org/10.1016/j.tsc.2016.11.006

Csikszentmihalyi, M. (1996). Flow and the psychology of discovery and invention. Harper Collins.

Demirkan, H. (2010). From theory to practice opinions. In A. Williams, M. J. Ostwald, \& H. H. Askland (Eds.), Creativity, design and education. Theories positions and challenges (pp. 56-59). ALTC.

Demirkan, H., \& Afacan, Y. (2012). Assessing creativity in design education: Analysis of creativity factors in the first-year design studio. Design Studies, 33(3), 262-278. https://doi.org/10.1016/j.destud.2011.11.005

Demirkan, H., \& Hasirci, D. (2009). Hidden dimensions of creativity elements in design process. Creativity Research Journal, 21(2-3), 294-301. https://doi.org/10.1080/10400410902861711

Denel, B. (1998). Temel tasarım ve değişim. In N. Teymur, \& T. A. Dural (Eds.), Temel Tasarım/Temel Eğitim (pp. 29-34). ODTÜ Mimarlık Fakültesi Yayınları.

Fink, A., \& Benedek, M. (2014). EEG alpha power and creative ideation. Neuroscience and Biobehavioral Reviews, 44, 111123. https://doi.org/10.1016/j.neubiorev.2012.12.002

Forgionne, G., \& Newman, J. (2007). An experiment on the effectiveness of creativity enhancing decision making support systems. Decision Support Systems, 42(4), 2126-2136. https://doi.org/10.1016/j.dss.2006.05.009

Gabriel, A., Monticolo, D., Camargo, M., \& Bourgault, M. (2016). Creativity support systems: A systematic mapping study. Thinking Skills and Creativity, 21, 109-122. https://doi.org/10.1016/j.tsc.2016.05.009

Gagné, R. M. (1985). The conditions of learning and theory of instruction. Holt, Rinehart and Winston.

Gorska, R., \& Sorby, S. (2008). Testing instruments for the assessment of 3-D spatial skills. Proceedings from the American Society for Engineering Education (ASEE) Annual Conference (pp. 22-25). Pittsburgh, PA.

Greene, S. L. (2002). Characteristics of applications that support creativity. Communications of the ACM, 45(10), 100-104. https://doi.org/10.1145/570907.570941

Harley, J. M., Poitras, E. G., Jarrell, A., Duffy, M. C., \& Lajoie, S. P. (2016). Comparing virtual and location-based augmented reality mobile learning: Emotions and learning outcomes. Educational Technology Research and Development, 64(3), 359-388. https://doi.org/10.1007/s11423-015-9420-7

Hasirci, D., \& Demirkan, H. (2007). Understanding the effects of cognition in creative decision-making: A creativity model for enhancing creativity in the design studio process. Creativity Research Journal, 19(2-3), 259-271. https://doi.org/10. 1080/10400410701397362 
Hennessey, B. A., \& Amabile, T. M. (2010). Creativity. Annual Review of Psychology, 61(1), 569-598. https://doi.org/10. 1146/annurev.psych.093008.100416

Ho, C. H. (2006). Spatial cognition in design [Unpublished doctoral dissertation]. Georgia Institute of Technology, Atlanta, Georgia.

Horn, D., \& Salvendy, G. (2006). Consumer-based assessment of product creativity: A review and reappraisal. Human Factors and Ergonomics in Manufacturing, 16(2), 155-175. https://doi.org/10.1002/hfm.20047

Hussein, M., \& Nätterdal, C. (2015). The benefits of virtual reality in education - A comparision Study. [Unpublished thesis]. University of Gothenburg, Göteborg, Sweden.

Jackson, S. A., \& Marsh, H. W. (1996). Development and validation of a scale to measure optimal experience: The Flow State Scale. Journal of Sport and Exercise Psychology, 18(1), 17-35. https://doi.org/10.1123/jsep.18.1.17

Jeamu, L., Kim, Y., \& Lee, Y. (2008). A web-based program to motivate underachievers learning number sense. International Journal of Instructional Media, 35(2), 185-194.

Jou, M., \& Wang, J. (2013). Investigation of effects of virtual reality environments on learning performance of technical skills. Computers in Human Behavior, 29(2), 433-438. https://doi.org/10.1016/j.chb.2012.04.020

Karakaya, A. F., \& Demirkan, H. (2015). Collaborative digital environments to enhance the creativity of designers. Computers in Human Behavior, 42, 176-186. https://doi.org/10.1016/j.chb.2014.03.029

Kaur, D. P., Mantri, A., \& Horan, B. (2019). Design implications for adaptive augmented reality based interactive learning environment for improved concept comprehension in engineering paradigms. Interactive Learning Environments, https://doi.org/10.1080/10494820.2019.1674885

Keller, J. M. (1987). Development and use of the ARCS model of instructional design. Journal of Instructional Development, 10(3), 2-10. https://doi.org/10.1007/BF02905780

Keller, J. M. (2010). Motivational design for learning and performance. Springer US. http://link.springer.com/10.1007/978$1-4419-1250-3$

Keller, J. M., \& Litchfield, B. C. (2002). Motivation and performance. Trends and Issues in Instructional Design and Technology, 2, 89-92.

Keller, J., \& Suzuki, J. (2004). Learner motivation and e-learning design: A multinationally validated process. Journal of Educational Media, 29(3), 229-239. https://doi.org/10.1080/1358165042000283084

Kilmon, C. A., Brown, L., Ghosh, S., \& Mikitiuk, A. (2010). Immersive virtual reality simulations in nursing education. Nursing Education Perspectives, 31(5), 314-317. PMID: 21086871. https://pubmed.ncbi.nlm.nih.gov/21086871/

Klein, E., \& Dologite, D. (2000). The role of computer support tools and gender composition in innovative information system idea generation by small groups. Computers in Human Behavior, 16(2), 111-139. https://doi.org/10.1016/ S0747-5632(00)00013-3

Lau, K. W., \& Lee, P. Y. (2015). The use of virtual reality for creating unusual environmental stimulation to motivate students to explore creative ideas. Interactive Learning Environments, 23(1), 3-18. https://doi.org/10.1080/10494820. 2012.745426

Linn, M. C., \& Petersen, A. C. (1985). Emergence and characterization of sex differences in spatial ability: A meta-analysis. Child Development, 56(6), 1479-1498. https://doi.org/10.2307/1130467

Liu, X., Li, Y., Pan, P., \& Li, W. (2011). Research on computer-aided creative design platform based on creativity model. Expert Systems with Applications, 38(8), 9973-9990. https://doi.org/10.1016/j.eswa.2011.02.032

McKim, R. (1972). Experiences in visual thinking. Cole Publishing.

Merchant, Z., Goetz, E. T., Cifuentes, L., Keeney-Kennicutt, W., \& Davis, T. J. (2014). Effectiveness of virtual reality-based instruction on students' learning outcomes in K-12 and higher education: A metaanalysis. Computers \& Education, 70, 29-40. https://doi.org/10.1016/j.compedu.2013.07.033

Mishra, P., \& The Deep-Play Research Group. (2012). Rethinking technology \& creativity in the 21st century: Crayons are the future. TechTrends, 56(5), 13-16. https://doi.org/10.1007/s11528-012-0594-0 doi:10.1007/s11528-012-0594-0

Mishra, P., \& Henriksen, D. (2018a). Crayons are the future. In P. Mishra, \& D. Henriksen (Eds.), Creativity, technology \& education: Exploring their convergence (pp. 9-16). Springer International Publishing.

Mishra, P., \& Henriksen, D. (2018b). A new definition of creativity. In P. Mishra, \& D. Henriksen (Eds.), Creativity, technology \& education: Exploring their convergence (pp. 17-23). Springer International Publishing.

Nusbaum, E. C., \& Silvia, P. J. (2011). Are openness and intellect distinct aspects of openness to experience? A test of the O/I model. Personality and Individual Differences, 51(5), 571-574. https://doi.org/10.1016/j.paid.2011.05.013

Oxman, R. (2002). The thinking eye: Visual re-cognition in design emergence. Design Studies, 23(2), 135-164. https://doi. org/10.1016/S0142-694X(01)00026-6

Pandey, M., Luthra, V., Yammiyavar, P. G., \& Anita, P. Y. (2015). Role of Immersive Virtual Reality in Fostering Creativity among Architecture Students. The Third International Conference on Design Creativity. Bangalore, India.

Pausch, R., Shackelford, M. A., \& Proffitt, D. (1993, October). A user study comparing head-mounted and stationary displays. In Virtual reality, 1993. IEEE symposium on research frontiers (pp. 41-45). IEEE. https://ieeexplore.ieee.org/ abstract/document/378265/citations\#citations.

Peters, M., Laeng, B., Latham, K., Jackson, M., Zaiyouna, R., \& Richardson, C. (1995). A redrawn Vandenberg \& Kuse mental rotations test: Different versions and factors that affect performance. Brain and Cognition, 28(1), 39-58. https://doi. org/10.1006/brcg.1995.1032 
Ran, Y., \& Zhenbiao, W. (2011). Virtual and augmented reality applications in industrial design. 3rd International Conference on Machine Learning and Computing (Vol. 4, pp. 245-249).

Riva, G. (2006). Virtual reality as communication tool: A sociocognitive analysis. Virtual Reality, 8(4), 462-468. https://doi. org/10.1162/105474699566341

Schnabel, M. A., Wang, X., \& Kvan, T. (2008). Touching the untouchable: Virtual-, augmented-, and reality. In International conference on the association for computer aided architectural design research in Asia.

Schön, D. A. (1985). The design studio: An exploration of its traditions and potentials. RIBA Publications Limited.

Schön, D. A. (1987). Educating the reflective practitioner: Toward a new design for teaching and learning in the professions (1st ed.). Jossey-Bass.

Schwind, V., Knierim, P., Haas, N., \& Henze, N. (2019). Using presence questionnaires in virtual reality. Human-Computer Interaction, $\mathrm{CHI}$.

Sha, L., Looi, C., Chen, W., Seow, P., \& Wong, L. (2012). Recognizing and measuring self-regulated learning in a mobile learning environment. Computers in Human Behavior, 28(2), 718-728. https://doi.org/10.1016/j.chb.2011. 11.019

Shepard, R. N., \& Metzler, J. (1971). Mental rotation of three-dimensional objects. Science, 171(3972), 701-703. https:// doi.org/10.1126/science.171.3972.701

Shneiderman, B. (2002). Inventing discovery tools: Combining information visualization with data mining. Information Visualization, 1(1), 5-12. https://doi.org/10.1057/palgrave.ivs.9500006

Shneiderman, B. (2007). Creativity support tools: Accelerating discovery and innovation. Communications of the ACM, 50 (12), 20-32. https://doi.org/10.1145/1323688.1323689

Shneiderman, B., Fischer, G., Czerwinski, M., Resnick, M., Myers, B., Candy, L., Eisenberg, M., Giaccardi, E., Hewett, T., Jennings, P., Kules, B., Nakakoji, K., Nunamaker, J., Pausch, R., Selker, T., Sylvan, E., \& Terry, M. (2006). Creativity support tools: Report from a US National Science Foundation sponsored workshop. International Journal of Human-Computer Interaction, 20(2), 61-77.

Sopher, H., Fisher-Gewirtzman, D., \& Kalay, Y. E. (2019). Going immersive in a community of learners? Assessment of design processes in a multi-setting architecture studio. British Journal of Educational Technology, 50(5), 21092128. https://doi.org/10.1111/bjet.12857

Sorby, S. A. (2007). Developing 3D spatial skills for engineering students. Australasian Journal of Engineering Education, 13(1), 1-11. https://doi.org/10.1080/22054952.2007.11463998

Sun, C., Hu, W., \& Xu, D. (2019). Navigation modes, operation methods, observation scales and background options in UI design for high learning performance in VR-based architectural applications. Journal of Computational Design and Engineering, 6(2), 189-196. https://doi.org/10.1016/j.jcde.2018.05.006

Teklemariam, H. G., Kakati, V., \& Das, A. K. (2014). Application of VR technology in design education. In International conference on engineering and product design education (pp. 117-122). The Netherlands: University of Twente.

Thorsteinsson, G. (2013). Developing an understanding of the pedagogy of using a virtual reality learning environment (VRLE) to support innovation education. In L. V. Shavinina (Ed.), The Routledge International Handbook of Innovation education (pp. 456-470). Routledge.

Vandeleur, S., Ankiewicz, P. J., de Swardt, A. E., \& Gross, E. J. (2001). Indicators of creativity in a technology class: A case study. South African Journal of Education, 21(4), 268-273. https://doi.org/10.4314/SAJE.V21/4.24914

Vandenberg, S. G., \& Kuse, A. R. (1978). Mental rotations, a group test of three-dimensional spatial visualization. Perceptual and Motor Skills, 47(2), 599-604. https://doi.org/10.2466/pms.1978.47.2.599

Varinlioglu, G., Akcam, S., \& Halici, S. (2015). Computational approaches for basic design education: pedagogical notes based on an intense student workshop. In XIX Congresso da Sociedade Ibero americana de Gráfica Digital 2015. Florianopolis. http://www.proceedings.blucher.com.br/article-details/computational-approaches-for-basicdesign-education-pedagogical-notes-based-on-an-intense-student-workshop-22369

Veale, T., Feyaerts, K., \& Forceville, C. (2013). Creativity and the agile mind: A multi-disciplinary study of a multi-faceted phenomenon (Vol. 21). Walter de Gruyter.

Vergara, D., Lorenzo, M., \& Rubio, M. P. (2015). Virtual environments in materials science and engineering: The students' opinion. In H. Lim (Ed.), Handbook of research on recent developments in materials science and corrosion engineering education (1st ed., Vol. 8, pp. 148-165). IGI Global.

Vergara, D., Rubio, M. P., \& Lorenzo, M. (2017). On the design of virtual reality learning environments in engineering. Multimodal Technologies and Interaction, 1(2), 11. https://doi.org/10.3390/mti1020011 doi:10.3390/mti1020011

Wang, K., \& Nickerson, J. V. (2017). A literature review on individual creativity support systems. Computers in Human Behavior, 74, 139-151. https://doi.org/10.1016/j.chb.2017.04.035

Wei, X., Weng, D., Liu, Y., \& Wang, Y. (2015). Teaching based on augmented reality for a technical creative design course. Computers \& Education, 81, 221-234. https://doi.org/10.1016/j.compedu.2014.10.017 doi:10.1016/j.compedu.2014. 10.017

Witmer, B. G., \& Singer, M. J. (1998). Measuring presence in virtual environments: A presence questionnaire. Presence, 7 (3), 225-240. https://doi.org/10.1162/105474698565686

Witmer, B. G., \& Singer, M. J. (2005). The factor structure of the presence questionnaire. Presence, 14(3), 298-312. https:// doi.org/10.1162/105474605323384654 
Yalcinalp, S., \& Avci, U. (2019). Creativity and emerging digital educational technologies: A systematic review. The Turkish Online Journal of Educational Technology, 18(3), 25-45.

Yang, X., Cheng, P. Y., Lin, L., Huang, Y. M., \& Ren, Y. (2019). Can an integrated system of electroencephalography and virtual reality further the understanding of relationships between attention, meditation, flow state, and creativity? Journal of Educational Computing Research, 57(4), 846-876. https://doi.org/10.1177/ 0735633118770800

Yang, X., Lin, L., Cheng, P. Y., Yang, X., Ren, Y., \& Huang, Y. (2018). Examining creativity through a virtual reality support system. Education Technology Research Development, 66(5), 1231-1254. https://doi.org/10.1007/s11423018-9604-z 